\title{
Forsinket forløsning av tvilling 2
}

\author{
Tvillinger er to søsken som har vært sammen i livmoren og som fødes \\ samtidig. Dette er imidlertid ikke alltid tilfellet.
}

Heidi Frostad Sivertsen

Kvinne-/barnklinikken

Nordlandssykehuset, Bodø

En kvinne i slutten av 30-årene som var spontant tvillinggravid ble innlagt i lokalsykehus i svangerskapsuke $22+4$ på grunn av feber og infeksjonssymptomer. Hun var fra tidligere stort sett frisk og hadde født tre barn til termin. Feberen hadde vart i anslagsvis 24 timer forut for innleggelsen. Hun hadde siste uken før innleggelsen også hatt økende vaginal utflod, og siste døgnet økende kynneraktivitet. Hun anga smerter $i$ hoftene og nedover lårene, og hadde hatt en sparsom vaginalblødning innleggelsesdagen. Ved innkomst på lokalsykehusets fødeavdeling hadde hun temperatur $39^{\circ} \mathrm{C}$, blodtrykk $100 / 50 \mathrm{~mm} \mathrm{Hg}$ og puls 90. Blodprøver viste leukocytter $18,8 \cdot 10^{9} / \mathrm{l}\left(4,0-11 \cdot 10^{9} / \mathrm{l}\right)$ og CRP $165 \mathrm{mg} / \mathrm{l}$ $1<10 \mathrm{mg} / \mathrm{ll}$. Livmorhalsen var avflatet, mormunnen åpen for $4 \mathrm{~cm}$ og med en spent vannblære. Pasienten var definert til å være i aktiv fødsel. Det ble tatt blodkulturer, dyrking fra vagina og urin. Hun fikk $1 \mathrm{~g}$ Paracetamol tabletter på grunn av feber. Abdominal ultralyd viste to vitale fostre og to atskilte placentaer som lå henholdsvis anteriort og posteriort. Det var normal tilvekst hos fostrene og normal fostervannsmengde hos begge tvillinger. Det ble startet med intravenøs cefuroksim $1,5 \mathrm{~g} \times 3$ og metronidazol $500 \mathrm{mg} \times 3$ på mistanke om korioamnionitt. Hun hadde økende riaktivitet, og det ble derfor besluttet å overføre henne til fødeavdeling ved sentralsykehus. Det ble gitt tokolyse i form av terbutalin 0,25 mg subkutant før transport for å unngå mulig transportfødsel.

Andelen tvillingsvangerskap i Norge har de siste ti år vært på rundt $2 \%$. I om lag $70 \%$ av tvillingsvangerskapene er det toeggede tvillinger, mens i $30 \%$ eneggede. Insidensen av eneggede tvillinger er relativt stabil på 3-5/1 000, mens insidensen av toeggede varierer og avhenger av flere faktorer, som mors alder, paritet, ovulasjonsstimulerende medikamenter og in vitro-fertilisering. Tvillingsvangerskap er forbundet med høyere perinatal mortalitet, høyere forekomst av intrauterin veksthemning, økt risiko for føtale misdannelser og premature fødsler. En tvillingmor har økt risiko for blant annet spontanabort, hyperemesis gravidarum, hypertoni, preeklampsi og større postpartumblødninger (1).

Tvillinger kan ha felles eller separat placenta. Toeggede tvillinger vil ha separate placentaer, mens eneggede tvillinger kan ha felles eller separat placenta, avhengig av når delingen av det befruktede egget skjer (fig 1). Vår pasient hadde fostre med hver sin separate placenta (dikoreote) og lå i separate fostersekker (diamniote).

Ved innkomst i Nordlandssykehuset, Bodø ti timer etter primærinnleggelsen, var kvinnen afebril, uterus var uøm og hun hadde tiltakende kontraksjoner. Ved undersøkelse fant man to vitale fostre, tvilling $1 \mathrm{i}$ hodeleie og tvilling 2 i tverrleie. Ved vaginalundersøkelse var livmorhalsen nærmest helt åpen og fødsel var uunngåelig. Foreldrene ble informert om svært dårlig prognose for fostrene på grunn av ekstrem prematuritet og sannsynlig korioamnionitt.

Korioamnionitt er en betennelse i fosterhinner og morkake og er en føtal sykdom. Infeksjonen forårsakes oftest av oppadstigende mikroorganismer fra vagina. Kvinnen vil kunne få en endometritt/deciduitt som følge av en korioamnionitt, med generelle infeksjonssymptomer som feber og magesmerter/smerter over uterus, eventuelt sepsis eller septisk sjokk. Fosteret vil som oftest bli takykard som følge av infeksjonen. I vårt tilfelle, hvor fostrene hadde separate placentaer og to fostersekker, kunne man tenke seg at bare den ene tvillingen var affisert av infeksjonen. Prematur fødsel defineres som fødsel før svangerskapsuke 37. Prevalensen av prematur fødsel i Norge er 6-7\%. I tvillingsvangerskap er prevalensen av premature fødsler høyere, i enkelte materialer oppgitt til nesten $50 \%$. Preterm prematur vannavgang (preterm prelabour rupture of membranes, PPROM) er hyppigere i tvillingsvangerskap, med en forekomst på $7-8 \%$ mot $2-4 \%$ i svangerskap med enlinger (2). Ekstrem prematuritet er definert til å være fødsel under 27 svangerskapsuker og/ eller fødselsvekt $<1000 \mathrm{~g}$. Mortaliteten ved ekstrem prematuritet har avtatt de siste 30 årene. I 1980-årene var overlevelsen for denne gruppen $30-40 \%$, mens den nå er på rundt $70 \%$ for hele gruppen, dog lavere jo lavere svangerskapsalder $(3,4)$.

En halv time etter ankomst i Nordlandssykehuset tilkom spontan vannavgang på tvilling 1 . En og en halv time etter vannavgang ble tvilling 1 født, en levende gutt med fødselsvekt $480 \mathrm{~g}$, lengde $29 \mathrm{~cm}$ og hodeomkrets $20 \mathrm{~cm}$. Han døde på grunn av immaturitet 3,5 timer etter fødselen. Placenta kom ikke etter fødselen, og det var ingen blødning. Tvilling 2 var nå i fotpresentasjon over bekkeninngangen. Man gjorde forsøk på amniotomi for å få videre fremgang i fødselen, men lyktes ikke da placenta til tvilling 1 la seg over indre mormunn. På grunn av sekundær risvekkelse ga man ristimulerende okstocininfusjon $i$ økende dosering inntil maksimal dose på $180 \mathrm{ml} / \mathrm{t} i$ over en time uten at kvinnen fikk rier. Ristimulerende infusjon ble seponert slik at kvinnen kunne få hvile gjennom natten.

Bakgrunnen for dette var at hun nå var afebril, hun hadde ingen magesmerter og var sirkulatorisk stabil. Det var ingen medisinsk indikasjon for at man måtte forløse henne umiddelbart. Det ble planlagt å starte ristimulerende infusjon igjen neste morgen. CRP hadde falt fra $165 \mathrm{mg} / \mathrm{l}$ til $105 \mathrm{mg} / \mathrm{l}$. Intravenøs antibiotika ble kontinuert i uendret dosering. Tilfellet ble diskutert på morgenmøtet om lag åtte timer etter fødsel av tvilling 1. En av kollegene hadde tidligere hørt om et tilfelle der man hadde forsøkt å forlenge svangerskapet etter fødsel av tvilling 1. Man diskuterte denne muligheten med paret som ble informert om at man måtte avslutte svangerskapet dersom kvinnens medisinske situasjon forverret seg. Paret var innforstått med dette. Kvinnen var fortsatt afebril, hadde ingen magesmerter og uterus var uøm og relaksert. Infeksjonsprøvene fortsatte à falle. Navlesnoren til tvilling 1 ble avsatt så langt opp i vagina som mulig. Man anbefalte sengeleie og hun fortsatte med uendret intravenøs antibiotikabehandling og fikk tromboseprofylakse med lavmolekylært heparin 5000 IE subkutant .

I svangerskapsuke 23+0, tre dager etter fødsel av tvilling 1, tilkom spontan vannavgang på tvilling 2. Det var klart fostervann og normal fosterlyd. Infeksjonsparametrene ble kontrollert annenhver dag. CRP var stabil rundt $40 \mathrm{mg} / \mathrm{l}$ og det var en lett leukocytose på 10-20.10/l, hvilket er normalt hos gravide. Det var sparsom oppvekst av ente- 

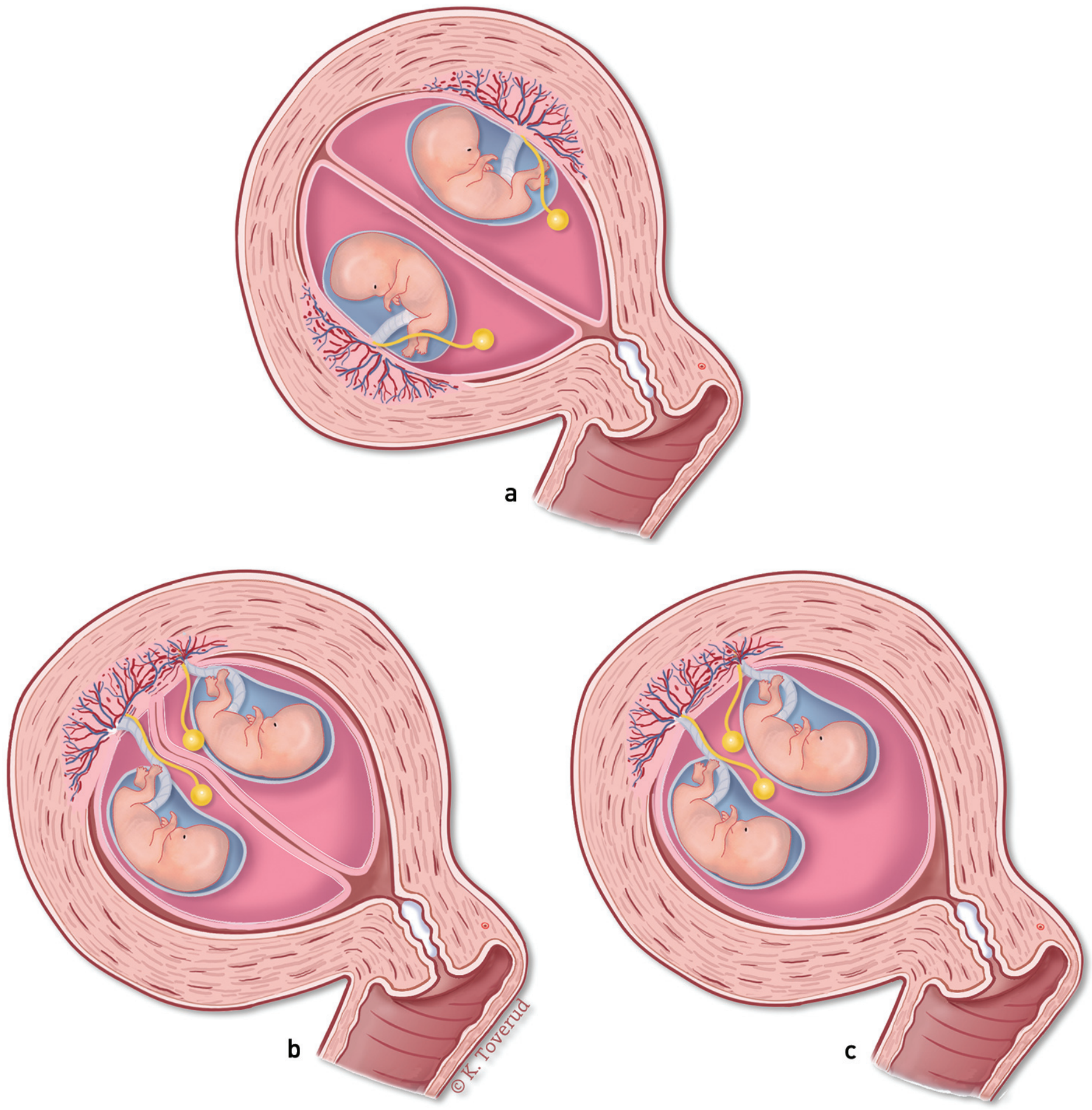

Figur 1 a) To separate placentaer/to fostersekker. b) En felles placenta/to fostersekker. c) En felles placenta/en fostersekk

rokokker og gruppe B-streptokokker i vaginalsekret, samt gruppe B-streptokokker fra huddyrking fra tvilling 1. Resistensbestemmelse viste at enterokokkstammen var følsom for både ampicillin, penicillin og amoksicillin. Etter å ha konferert mikrobiolog ble det fortsatt med uendret intravenøs cefuroksim og metronidazol. Ettersom hun nå var i svangerskapsuke $23+0$, valgte man å gi lungemodning i form av betametason $12 \mathrm{mg}$ intramuskulært, til tross for mistanke om korioamnionitt hos tvilling 1 og mulig subklinisk affeksjon av tvilling 2. Kvinnen ble observert med daglige temperaturmålinger, man lyttet daglig på fosterlyd og det ble tatt orienterende blodprøver annenhver dag.

Bruk av kortikosteroider til lungemodning er en av hovedårsakene til den reduserte morbiditeten og mortaliteten hos premature de siste 25-30 år. Lungene hos premature er umodne og mangler surfaktant som virker stabiliserende på alveolene. Steroider stimulerer surfaktantdanning og reduserer risikoen for blant annet akutt lungesviktsyndrom (infant respiratory distress syndrome), intracerebral blødning og nekrotiserende enterokolitt (5). Bivirkningene ved å gi steroider er faren for å maskere eventuelle infeksjonssymptomer hos mor og foster.

I svangerskapsuke 24+4, 14 dager etter fødsel av tvilling 1, fant man ved ultralydundersøkelse tvilling $2 i$ seteleie med fostervann $i$ nedre normalområde. Det var normal biometri, aktivt foster med tilvekst - $12 \%$ og normale funn etter dopplerundersøkelse av a. umbilicalis. Cervix var lukket og ble målt med transvaginal ultralyd til $32 \mathrm{~mm}$. I svangerskapsuke 25+1, 18 dager etter fødsel av tvilling 1 , bemerket kvinnen mindre fosterbevegelser og fostervannet var nå blitt 
grønnlig misfarget. Kvinnen var afebril og hadde ingen smerter over uterus. CRP var på $23 \mathrm{mg} / \mathrm{l}$ og leukocytter 13,0 $10 \%$ l. Fosteret var takykard med hjertefrekvens på 170, og man fant ved abdominal ultralyd anhydramnion, det vil si intet fostervann og foster $i$ tverrleie. Man mistenkte subklinisk korioamnionitt og valgte å forløse kvinnen med akutt sectio. Det ble født en levende jente med fødselsvekt $550 \mathrm{~g} \mathrm{(<10} \mathrm{prosentilen),}$ apgarskår var 5 og 7 etter henholdsvis 1 og 5 min. Arteriell syre-base-status var $\mathrm{pH} 7,19$ $(7,10-7,40)$ og $B E-6 \mathrm{mmol} / \mathrm{l}(-11-1 \mathrm{~mm} / \mathrm{l})$. Dyrking av begge placentaer viste sparsom vekst av Enterococcus faecalis, med usikker etiologisk betydning. Det var ikke oppvekst av gruppe B-streptokokker hos tvilling 2. Histologisk undersøkelse av placenta viste DC/DA tvillingplacenta, dvs. to separate placentaer og to separate fostersekker, hvor begge hadde uttalt funikulitt og korioamnionitt.

Barnet ble overflyttet til nyfødtintensivavdelingen og gitt respiratorbehandling. Hun ble respiratorbehandlet $i$ fem uker, videre lå hun med CPAP i 42 døgn. Enterokokker og Staphylococcus aureus ble påvist $i$ blodkulturer og hun ble sepsisbehandlet. Hun hadde initialt klassiske tegn til bronkopulmonal dysplasi, som var normalisert ved utreise. Hun hadde normal cerebral ultralyd ved gjentatte undersøkelser. Det var ingen tegn til prematur retinopati (retinopathy of prematurity, ROPI. Hun ble utskrevet etter fem måneder og fire dager, og veide da 2800 $g$, var $46 \mathrm{~cm}$ lang og med hodeomkrets $34,9 \mathrm{~cm}$. Hun ble sist kontrollert ved korrigert alder 21,5 måneder, det vil si alder ut fra beregnet termin, ikke fødselstidspunkt. Hun veide da 9500 gram (10-25 prosentilen) og var $79 \mathrm{~cm}$ lang $(3 \mathrm{~cm}<2,5$ prosentilen). Hun hadde aldersadekvat motorisk utvikling og normale funn ved undersøkelse av synspedagog. Hun hadde hatt en del luftveisproblemer $i$ form av kuldeutløst obstruksjon og brukte inhalasjonssteroider og inhalasjonsadrenergikum. Hun hadde utviklet laktoseintoleranse og fått påvist «fuglebryst», pectus carinatum. Hun er nå under observasjon med henblikk på autisme.

\section{Diskusjon}

I litteraturen er det beskrevet anslagsvis 400 tilfeller av forsinket forløsning av tvilling 2 $(6,7)$. Svangerskapsalder ved fødsel av tvilling 2 varierer i området svangerskapsuke 17-39 og intervallet mellom tvilling 1 og 2 kan være 1-153 dager. I en amerikansk kohortstudie beskrives ettårsoverlevelse hos forsinket forløst tvilling 2 på $56 \%$, og overlevelse hos ikke-forsinket tvilling 2 på $24 \%$. Forsinket forløsning av tvilling 2 før svangerskapsuke $30 \mathrm{og}$ i to dager eller mer, var assosiert med økt overlevelse. I en annen kohortstudie på samme populasjon var forsinket forløsning av tvilling 2 assosiert med redusert perinatal og neonatal mortalitet for tvilling 2 når første tvilling ble født i svangerskapsuke 22-23, og intervallet mellom tvillingene var mindre enn tre uker. Forsinket forløsning av tvilling 2 hadde ingen effekt på mortalitet når tvilling 1 ble født rundt eller etter svangerskapsuke 24 . Forutsetningen for at man bevisst bør vurdere forsinket forløsning av tvilling 2 , er at det ikke foreligger en felles placenta eller tvillinger $i$ samme fostersekk, at det ikke foreligger abruptio placenta, placenta previa, unormal føtal hjerteaksjon (føtal distress) eller alvorlig preeklamspi. Korioamnionitt er sannsynligvis en relativ kontraindikasjon ettersom det er beskrevet flere tilfeller med vellykket utfall hvor det har vært korioamnionitt hos en eller begge tvillinger. Hos mødrene er det beskrevet intrauterine infeksjoner hos opptil $30 \%$ og septikemi hos $5 \%$.

Det finnes ingen retningslinjer for håndtering av denne sjeldne obstetriske utfordringen. I kasuistikker og kohortstudier har man forsøkt å bruke gjeldende retningslinjer for truende preterm fødsel, og man diskuterer tokolyse, antibiotikabehandling, steroider, cerclage og sengeleie. En gruppe fra Nederland kom i en artikkel fra 2009 med forslag til en behandlingsprotokoll ved ønske om forsinket forløsning av tvilling 2 (8). Man anbefaler at man avnavler tvilling $1 \mathrm{i}$ nivå med cervix eller så høyt som mulig i vagina, gir intravenøs. bredspektret antibiotika ved infeksjonstegn, og eventuelt seponerer antibiotika ved normalisering av infeksjonsparametre og negative dyrkingsprøver. Videre anbefaler man profylaktisk tokolyse umiddelbart etter fødsel av tvilling 1 selv om riaktiviteten opphører, behandlingstid ikke oppgitt. Cerclage er det mest omstridte tiltaket og er anvendt $i$ ca. $60 \%$ av tilfellene beskrevet i litteraturen. Cerclage kan øke risikoen for preterm prematur vannavgang og korioamnionitt, men man har sett en tendens til at intervallet mellom tvillingene var noe lengre hos kvinnene som fikk dette. Gruppen anbefaler cerclage i de tilfellene der man ikke har tegn til infeksjon.

Kortikosteroider for lungemodning anbefales som engangsdose gitt i svangerskapsuke 24-34. Sengeleie er anbefalt uten at dette er diskutert nærmere, og det er ikke oppgitt noen referanser for å underbygge denne anbefalingen.

Den nasjonale veilederen i obstetrikk anbefaler tokolyse ved truende preterm fødsel for å oppnå effekt av kortikosteroider i svangerskapsuke 24-34, og individuell vurdering svangerskapsuke 23 . Tokolyse er kontraindisert ved mistanke om korioamnionitt, abruptio placenta, ved truende asfyksi eller alvorlig preeklampsi. Nødcerclage er et inngrep som gjøres på kvinner som er i aktiv fødsel, det kan vurderes i helt spesielle tilfeller, men har dårlig prognose og anbefales ikke. Kortikosteroider anbefales gitt i svangerskapsuke 24-34, med to doser betametason $12 \mathrm{mg}$ intramuskulært med 24 timers intervall.

Antibiotika skal gis ved prematur vannavgang. I retningslinjene fra den nasjonale veilederen før 2008, som var gjeldende på aktuelle tidspunkt for vår kasuistikk, var det anbefalt ampicillin peroralt, men intravenøs administrasjon ved sikre infeksjonstegn.

Den nye veilederen anbefaler initialt penicillin intravenøst $i$ tre dager med overgang til peroral behandling en uke etter resistensbestemmelse. Ved negativt dyrkingssvar behandles pasienten uansett en uke. Sengeleie er ikke anbefalt ettersom man ikke har noen dokumentasjon for at dette er en effektiv behandling ved truende preterm fødsel (9). Med tanke på sengeleie anbefalte man pasienten vår sengeleie med lov til å gå på toalettet i dagene etter fødsel av tvilling 1 , men dette er ikke nedfelt i noen prosedyre.

Dersom man kommer opp i en slik sjelden problemstilling, bør man anvende de gjeldende nasjonale anbefalinger for truende prematur fødsel og prematur vannavgang, samt tilgjengelig litteratur. Man bør vurdere å konferere med erfarne obstetrikere ved større fødeavdelinger, og inkludere pediatere i problemstillingen. Overflytting av pasienten til større avdeling kan selvsagt også vurderes, avhengig av den obstetriske og pediatriske kompetansen på stedet. Foreldrene må selvsagt informeres om situasjonen og de valg man står overfor, og man må være lydhør overfor deres ønsker.

Foreldrene har gitt samtykke til at artikkelen blir publisert.

\section{Heidi Frostad Sivertsen (f.1968)}

er spesialist i fødselshjelp og kvinnesykdommer og overlege ved Kvinne-/barnklinikken. Ingen oppgitte interessekonflikter.

\section{Litteratur}

. Fried A, Davis K, red. Williams Obstetrics 23. utg. Multifetal gestation. Maidenhead, Berkshire: McGraw-Hill Medical, 2010: 859-89.

2. Sela HY, Simpson LL. Preterm premature rupture of membranes complicating twin pregnancy: man agement considerations. Clin Obstet Gynecol 2011 54: $321-9$

3. Fellman V, Hellström-Westas L, Norman M et al. One-year survival of extremely preterm infants after active perinatal care in Sweden. JAMA 2009 301: 2225-33.

4. Markestad T, Kaaresen PI, Rønnestad A et al. Early death, morbidity, and need of treatment among extremely premature infants. Pediatrics 2005; 115 1289-98.

5. Roberts D, Dalziel SR. Antenatal corticosteroids for accelerating fetal lung maturation for women at risk of preterm birth. Cochrane Database Syst Rev 2006; nr. 3, CD004454

6. Zhang J, Hamilton B, Martin J et al. Delayed interval delivery and infant survival: a population-based study. Am J Obstet Gynecol 2004: 191: 470-6.

7. Oyelese Y, Ananth CV, Smulian JC et al. Delayed interval interval delivery in twin pregnancies in the United States: impact on perinatal mortality and morbidity. Am J Obstet Gynecol 2005; 192: 439-44.

8. Wouters KA, Gianotten J, Bayram N et al. Term life birth after late abortion of the first twin. Acta Obstet Gynecol Scand 2009; 88: 1148-52.

9. Veileder i fødselshjelp 2008. www.legeforeningen.no/id/131068.0 (21.5.2011)

Mottatt 28.1. 2011, første revisjon innsendt 30.5. 2011, godkjent 7.7. 2011. Medisinsk redaktør Lars Frich. 